\title{
Análisis del Código del Samurái de Daidoji Yuzan desde una perspectiva económica
}

\author{
José Aguilar Gómez
}

Resumen: Este trabajo sigue la tendencia reciente de estudiar el contenido económico de obras que no revisten un carácter económico, ya sean obras filosóficas, de la literatura, etc. El Bushido era un código de conducta y de ética que existió en Japón en la Edad Media, desde el siglo XII hasta finales del siglo XIX. El Bushido como filosofía y código de conducta surgió en el siglo XII y estará en vigor durante siete siglos hasta su abolición en 1868, con la revolución industrial y el desmantelamiento de la sociedad tradicional aunque ello no quita que continuase presente en el Japón de la vida política, social y económica. Responde al objetivo trazado de analizar el contenido económico del texto de Yuzan.

Palabras clave: Bushido, código de conducta, Japón,Yuzán, Economía, historia económica.

Fecha de recepción: 9 de julio de 2017.

Fecha de admisión definitiva: 19 de julio de 2018.

\section{Analysis of the Samurai Code of Daidoji Yuzan from an economic perspective}

Abstract: This work follows the recent trend of studying the economic content of works that do not have an economic character, whether they are philosophical works, literature, etc. The Bushido was a code of conduct and ethics that existed in Japan in the Middle Ages, from the 12th century until

\section{Analyse du Code Samouraïde Daidoji Yuzan} d'un point de vue économique

Résumé: Ce travail s'inscrit dans la tendance récente de l'étude du contenu économique des œuvres non économiques, telles que les œuvres philosophiques, les œuvres littéraires, etc. Le Bushido était un code de conduite et d'éthique qui existait au Japon au Moyen Âge, du Xlle siècle à la fin du XIXe siècle. 
the end of the 19th century. The Bushido as a philosophy and code of conduct emerged in the twelfth century and will be in force for seven centuries until its abolition in 1868 , with the industrial revolution and the dismantling of traditional society although this does not mean that it remains present in Japan of life political, social and economic. It responds to the objective of analyzing the economic content of Yuzan's text.

Key words: Bushido, code of conduct, Japan, Yuzan, Economy, economic history.
La philosophie et le code de conduite du Bushido sont apparus au XIle siècle et étaient en vigueur pendant sept siècles, jusqu'à leur abolition en 1868, avec la révolution industrielle et le démantèlement de la société traditionnelle, bien que cela n'enlève rien à sa présence continue au Japon dans la vie politique, sociale et économique. II répond à l'objectif déclaré d'analyser le contenu économique du texte de Yuzan.

Mots clé: Bushido, code de conduite, Japon, Yuzan, économie, histoire économique.

\section{Introducción}

El Bushido era un código de conducta y de ética que existió en Japón en la Edad Media, desde el siglo XII hasta finales del siglo XIX. Lo mismo que en Europa existía en aquella época el código de la caballería, en Japón los guerreros japoneses y en especial, los samuráis tenían también el suyo propio. El Bushido como filosofía y código de conducta surgió en el siglo XIl y estará en vigor durante siete siglos hasta su abolición en 1868, con la revolución industrial y el desmantelamiento de la sociedad tradicional aunque ello no quita que continuase presente en el Japón de la vida política, social y económica, etc., Para más información sobre la permanencia del Bushido en el Japón de hoy ver Aguilar (2009).

Esta filosofía se plasmó a comienzos del siglo XVII en un libro llamado El código del samuray. Se trata de un código de conducta escrito por Daidoji Yuzan' escritor prominente de aquella época, poeta y experto en artes militares que hizo una recopilación de una serie de actividades, comportamientos y filosofías, sobre cómo debería actuar un samurái en tiempos de guerra y en tiempos de paz. Dicho código y la filosofía que contiene, constituye un tratado único sobre las leyes y preceptos internos de los samuráis. Asimismo, cubre todos los aspectos de sus vidas, incluyendo a toda una serie de cuestiones económicas tales como el comercio, la recaudación de los impuestos, la industria, la gestión del dinero, etc.

Este trabajo sigue la tendencia reciente de estudiar el contenido económico de obras que no revisten un carácter económico, ya sean obras filosóficas, de la literatura, etc. Esto último implica que nos encontramos ante un material denominado pensamiento económico difuso, puesto que no se encuentra reflejado en los manuales 
de economía, sino que se difunde a lo largo de las obras en la medida en que lo económico forma parte de la vida humana. En este sentido, vamos a realizar un estudio sobre el contenido económico de esta obra. Existen numerosas filosofías y códigos de conducta orientales, pero hemos considerado adecuado escoger esta principalmente porque fue la predominante en Japón durante ocho siglos, estuvo influenciada por otras filosofías y religiones orientales como el Budismo, Confucianismo y el Sintoísmo y hoy en día todavía quedan restos de esta filosofía en Japón.

La estructura de este trabajo consta de varias partes bien diferenciadas que están concatenadas por un hilo conductor que responde al objetivo trazado: analizar el contenido económico del texto de Yuzan. Tras un primer capítulo introductorio pasaremos directamente al estudio de los aspectos económicos de esta filosofía, examinando cuestiones como los sujetos económicos, necesidades, actividades productivas, etc. A continuación se estudiará un apartado importante dentro de dicho estudio del contenido económico que se denomina Vía de la Economía, un modelo económico de comportamiento que es la base económica de esta filosofía. Seguidamente, analizaremos si este modelo económico se mantiene o no en el Japón actual. Finalmente, en la última parte de este trabajo se desarrollan las conclusiones que se desprenden del mismo.

\section{Los sujetos económicos}

\section{I. La clase dirigente}

En la obra de Yuzan se puede ver reflejada claramente la estructura política y organizativa del estado japonés de la época. Japón vivió bajo un régimen feudal en el que todo el poder estaba concentrado en manos del Emperador, aunque en la práctica fuese el shogun (un híbrido entre primer ministro y dictador militar) el que realmente tomaba las decisiones políticas y económicas relevantes (ver cuadro $\mathrm{n}^{\circ} 1$ ). De este modo, el shogunato o Bakufu, cuya traducción literal sería "gobierno sobre la tierra", fue el gobierno militar que presidió Japón desde finales del siglo XII hasta la restauración Meiji de 1868. Después del Shogun venían los daimios. Eran el equivalente a los señores feudales europeos y debían lealtad al Shogun. Tenían, entre otras funciones, la de recaudar impuestos para el shogunato, mantener el orden y la justicia en sus feudos, etc.

Como complemento de lo anterior, en el libro de Yuzan se mencionan a otros empleados y cargos públicos que trabajan para la clase gobernante, como "jefes 
de departamento", "consejeros" o "comisionados". Con respecto a las funciones y obligaciones de los mismos, en la obra se hacen algunas referencias. En lo que al Emperador se refiere, no hay en el texto ninguna mención a sus tareas; mientras que en el caso del shogun, la gran mayoría de las alusiones se refieren a su papel como jefe del gobierno pero no se señala ninguna función específica o más concreta del que fuera primer ministro o dictador militar de Japón.

En cuanto a los daimios no hay muchas alusiones. En un lugar del texto se habla de las obligaciones públicas del daimio las cuales son de carácter fundamentalmente militar, debiendo tener un cuerpo de tropa preparado para una intervención inmediata, lo que requiere disponer de recursos económicos para ello. Así, p. ej.:

... supongamos que ocurriera mañana algún percance inesperado en la frontera de la provincia y que a nuestro contingente se le ordenara empezar inmediatamente a tomar posiciones; lo primero que se necesitaría es dinero...

\section{CUADRO $n^{\circ}$ I. Estructura social del Japón: siglos $\mathbf{X I I - X I X}$}

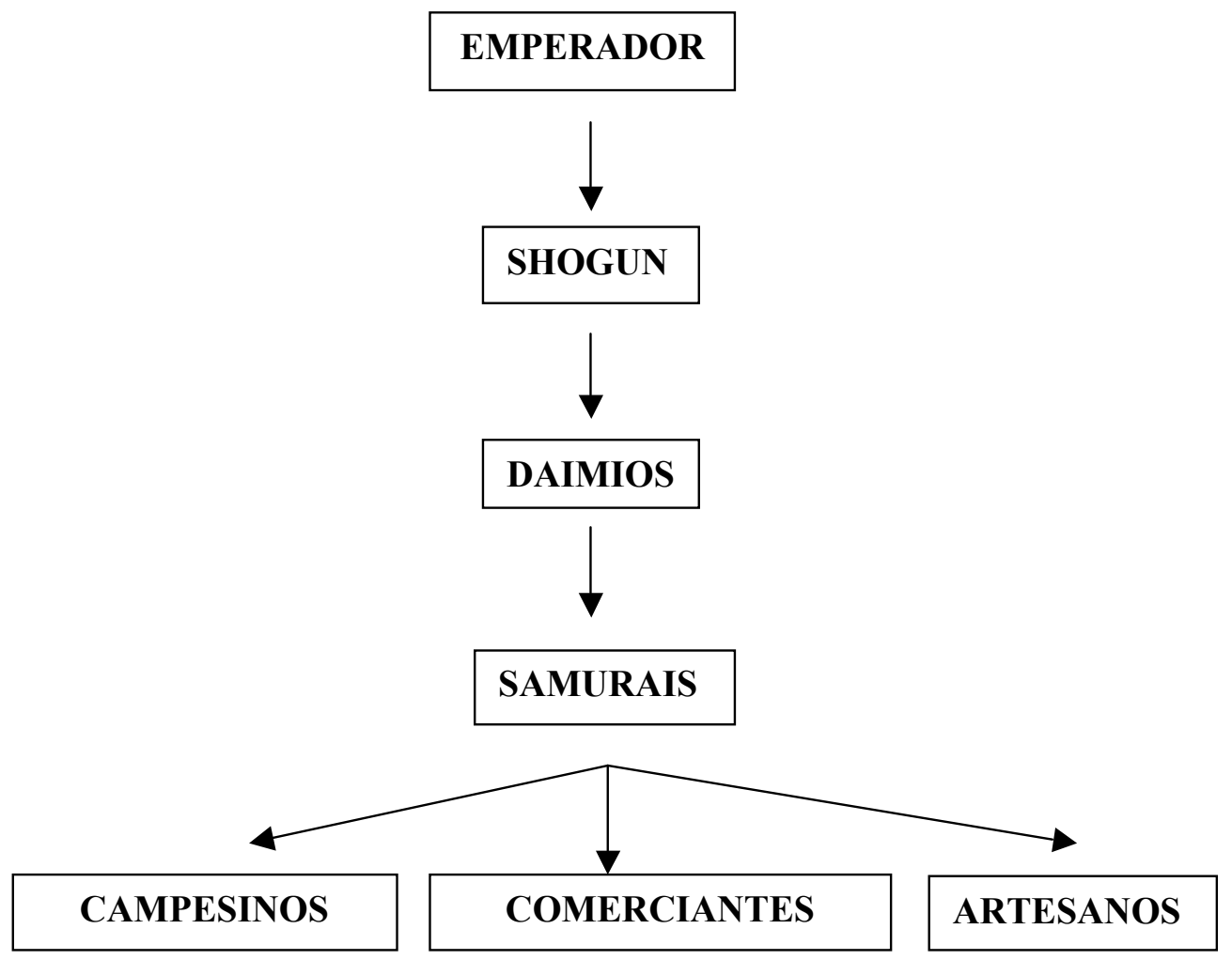

Fuente: SeGURA (2000). Elaboración propia. 
En el caso de los samuráis, sus funciones fundamentales eran militares y constructivas (p. 95); aun cuando en tiempo de paz llevaban a cabo otras tales como guardas, escoltas, inspecciones y similares No obstante, tenemos que destacar la función recaudatoria, a la que se hace alusión en el texto, y que coincide históricamente con una de las principales tareas que éstos tenían, sobre todo a partir del siglo $\mathrm{XVI}$. Se trata, por tanto, de la recaudación de los impuestos, fundamentalmente de las cosechas de arroz de los campesinos

Otras de las obligaciones de los mismos que se describe en la obra de Yuzan tiene que ver con el salario que perciben:

cuando se confiere a los daimyos el honor se asistir al gobierno del shogun en sus edificios y el gasto de esto es tan grande, tienen que pasar parte de él a sus feudatarios, pidiéndoles que contribuyan con un porcentaje de sus salarios...

De esta forma, los samuráis tenían la obligación de sufragar de sus propios bolsillos determinados gastos del señor feudal si este último lo consideraba oportuno.

De este modo, en El código del samuray se establece una especie de relación jerárquica dentro de los diferentes grupos de poder, cuyo elemento principal es la obediencia al superior, el cual, recíprocamente, protegería a los miembros de los escalones siguientes a su servicio, estableciéndose así una relación entre el "protector" y el "protegido". A este respecto, y en relación con los grupos que estaban en la parte inferior de la cadena de mando o jerarquía, se alude a ellos como los "vasallos", los "sirvientes" y el "feudatario.

\subsection{El pueblo}

En la obra de Yuzan hay una separación clara entre los grupos dirigentes y el pueblo. Las referencias a este último son diversas. En ocasiones se utilizan términos genéricos como "vasallos", "pueblo llano", "habitantes de la ciudad", "ciudadanos de la ciudad amurallada". También se alude a grupos específicos de población como "servidores", "criados". Pero sobre todo, llama la atención sobre lo que se denomina "las tres castas del pueblo": campesinos, artesanos y comerciantes. Efectivamente, se trata las diferentes clases sociales que componían el pueblo japonés y que son citadas en el libro de Yuzan.

La mayor parte de alusiones a estos grupos se hace para referirse a sus obligaciones, tales como pagar impuestos, ser leal al superior, ya fuera el samurái o cualquier otra persona de rango social superior, o simplemente al trabajo de dichos grupos 
sociales tales como en el caso del campesino era trabajar sus propias tierras o a las labores del artesano. No obstante, también se aprecia en la obra una actitud paternalista hacia ellos:

siempre hay que ser considerado con estas personas, amables con los campesinos que trabajan sus propias tierras y cuidadosos de que los artesanos no se arruinen. Y aunque puedas no pagar todas las deudas de una vez y puedas hacer transacciones con los habitantes de la ciudad y con los comerciantes, ciertamente debes pagarles algo de vez en cuando para no causar pérdidas e infortunio a estas castas. Los samuráis, cuyo deber es castigar a los bandidos y a los ladrones, no deben imitar el proceder de estos criminales.

En concreto, se recuerda a los samuráis las obligaciones siguientes con respecto a:

Campesinos: no exigirles más impuestos de lo debido y no obligarlos a realizar trabajos por la fuerza; ser amables con ellos.

Artesanos: pagar puntualmente el importe de los servicios y productos que se les encargue. Cuidar de que no se arruinen.

Comerciantes: no endeudarse indefinidamente con ellos sino que hay que pagarles algo de vez en cuando, para no causarles pérdidas; no prestarles dinero cobrándoles altos intereses.

Resumiendo, en la obra de Yuzan se describe claramente la estructura social de la época, con un amplio repertorio de términos y de indicaciones sobre dicha estructura social, aunque la mayor parte de las características, consejos y valoraciones que aparecen en la obra están relacionadas con la figura del samurái. Lo cual es lógico, ya que esta obra pretende ser una guía de conducta del samurái. En cualquier caso, y con todo ello, ahondando en lo señalado más arriba, es como si tuviésemos un retrato social de la época en que se escribió el libro.

\section{Necesidades económicas. Una visión general}

En la obra de Yuzan se pueden encontrar numerosas referencias a las necesidades humanas y a los deseos y esfuerzos de las personas para poder satisfacerlas. En la medida en que tales necesidades requieren de recursos escasos y susceptibles de usos alternativos para ser satisfechas, estaremos hablando de necesidades de naturaleza económica.

En algunos casos, el tema de las necesidades viene recogido de forma difusa. Por ejemplo, se alude a "los tiempos de necesidad", pero sin especificar a cuáles se 
refiere; en otras ocasiones se habla de "satisfacer las necesidades", "las necesidades de la vida bien cubiertas", etc.; o de forma más concreta se alude a temas como la educación, alimentación, vestido, alojamiento, etc. Referencias a todo ello se extienden a lo largo del texto. Vamos a ver en este apartado las tres necesidades que más aparecen en el texto: educación, vivienda y salud.

En El código del Samuray podemos encontrar numerosas referencias a las necesidades de educación, lo que en términos actuales llamamos formación de capital humano. No obstante, cuando hablamos de esto últimos, nos estamos refiriendo a la cantidad de conocimientos que posee una sociedad o un individuo, adquiridos mediante la escolarización formal o el aprendizaje por experiencia. La teoría del capital humano estudia su importancia en el proceso de crecimiento y/o desarrollo económico (Tamames y gallego, 2006, p. 78).

En la obra de Yuzan se emplea una terminología muy variada en este sentido: educación, estudio, aprendizaje, conocimiento, etc., son términos que se reparten por toda la obra y, de hecho, este último -conocimiento- es uno de los que más se utiliza en el texto. Además, al tema de la formación y el estudio se le dedica en el libro varios apartados y se le da mucha importancia.

Lo primero que tenemos que destacar en este punto es la enorme importancia que se le da en el texto a la educación de la persona, en este caso, del samurái: "le incumbe tener una buena educación y un amplio conocimiento de la razón de las cosas".... En realidad esto no es algo nuevo, sino que está en línea con la actitud de otras filosofías y religiones orientales tales como el confucianismo, budismo, taoísmo, etc.

Además, y, en línea con lo anterior, en el libro de Yuzan se critica la falta de formación y, sobre todo, el analfabetismo: "no existe excusa alguna para el analfabetismo". También se critica en otro lugar de la obra a los samuráis que no sabían escribir; Y se habla del que "se encontrará muy limitado por su falta de aprendizaje", de forma que se vuelve a insistir en la obra la problemática que se plantea por la falta de formación y la necesidad de "tener una comprensión general de los asuntos de tu propio país y de los países extranjeros".

En cuanto a los responsables específicos de la educación, se habla del maestro en diversas ocasiones a lo largo de la obra: cuando se habla de la enseñanza, ésta puede ser trasmitida por "padres", "maestros", "hermanos mayores"...Aunque también se utiliza el término "instructor" para referirse al que enseñaba las llamadas artes militares. Y respecto a los que pueden recibir las enseñanzas, se habla en el texto de "hijos", "alumnos" y "sobrinos". 
Respecto al tema de la vivienda en El código del samuray existen una serie de alusiones y menciones al tema, así como al modo en que debe abordarse la satisfacción de esta necesidad humana. Para empezar, se utilizan términos como "casa", "casa feudal", "cabaña" "residencia", "refugio", "hogar", "propiedades", "alojamiento", "castillo"..., para referirse a ello.

En el libro de Yuzan, las viviendas son descritas con una serie de características muy definidas. En primer lugar las casas tienen que ser casas adecuadas al rango social del samurái: "la residencia del samuray tiene buena apariencia por fuera y es digna y tranquila por dentro. Ello redundará en beneficio del buen nombre de su señor y de él mismo". En segundo lugar, se aconseja que las casas sean austeras tanto en la construcción como en la decoración. Por ejemplo, aludiendo a la ceremonia del té, que solía celebrarse en recintos especiales con características y ornamentación determinadas. Se trataba de lugares austeros sin lujo u ostentación con techo de junco, columnas de madera natural y vigas de bambú, según se afirma en el texto. Tales características se podían aplicar también a los utensilios: "vasijas de té hechas por alfareros modernos y teteras de tierra cocida, siendo todo muy barato".

En definitiva, el libro de Yuzan plantea en la construcción de la vivienda del samurái un equilibrio difícil entre la buena apariencia, comodidad, solidez...; y, al mismo tiempo, sencillez, austeridad, provisionalidad... Así, propone que, en determinadas ocasiones, los gastos de construcción no sean demasiado elevados con el objeto de evitar deudas (caso de incendio y de guerra); sin embargo, también aconseja invertir el dinero adecuado en las casas con el fin de evitar desembolsos en el futuro en arreglos y reformas. En resumen, los gastos no deben ser elevados ni excesivamente escuetos; sino los precisos. Todo ello nos remite a la vía de la economía de la que hablaremos más adelante.

\section{Actividades productivas}

Para satisfacer las necesidades anteriores se requieren una serie de actividades productivas que vamos a estudiar en este apartado. De este modo, analizaremos las referencias y alusiones que se hacen en la obra de Yuzan hacia los diferentes sectores económicos y actividades productivas, lo que nos permitirá descubrir, al menos en parte, cómo funcionaba en términos económicos el Japón del Bushido.

Entrando ya en el estudio de los sectores productivos, en la época en que se escribió El código del samuray, la agricultura era el sector más importante de la economía 
japonesa. En la obra de Yuzan se alude a la agricultura, a veces de forma indirecta, cuando se habla de "posesiones", "propiedades", "castillos", ya que la inmensa mayoría de estas propiedades contenían tierras cultivables; incluso cuando se habla de "hacerse cargo de la administración", también se refiere indirectamente a cuestiones relacionadas con el sector primario, porque en muchos casos estas administraciones incluían las tierras cultivables. En otras ocasiones las alusiones son directas, por ejemplo, cuando se habla de los "campesinos", o cuando se alude "a los campesinos del país". En otro lugar de la obra aparece el término "jornaleros", aunque no especifica ni se concreta a qué clase de jornaleros se refiere.

Asimismo, se hacen algunas referencias a lo largo de la obra a algunos cultivos y productos agrícolas, tales como el "arroz", que se menciona con relativa frecuencia, lo cual no es de extrañar ya que era el principal alimento de la población y es lógico que sea aludido. También se mencionan otros productos, como las "judías", el "algodón", el "bambú". Igualmente, se habla de la ganadería, citándose a los "caballos" y al "buey".

Por otra parte, hay en la obra alusiones indirectas a la actividad pesquera, la cual era un subsector muy importante en el Japón. Sin embargo, conviene advertir que la mayor parte de estas menciones, igual que se ha visto en el caso de la agricultura, se hacen para referirse a la alimentación de los samuráis, citando al pescado como alimento.

En lo que al sector secundario se refiere, existen en el texto algunas alusiones sobre la artesanía, aunque sin precisar explícitamente las especialidades concretas, con la excepción de una breve mención al "herrero". No olvidemos que el artesano, además de ser considerado una casta social, tenía cierta importancia en la economía del país, entre otros motivos porque se ocupaban de las cuestiones relacionadas con la construcción y mantenimiento de ciertas armas, tales como la espada japonesa, tanto la de hierro (katana), como la de madera (bokken).

Las pocas referencias a la artesanía que se hacen en la obra aparecen, sobre todo, cuando se reclama un buen trato para con ellos. Por ejemplo, cuando se aconseja pagar los artículos que se compran o encargan a los artesanos: "no debe encargar artículos a los artesanos y después descuidar su pago"; "Siempre hay que ser considerado con estas personas... y cuidadosos de que los artesanos no se arruinen". En segundo lugar, cuando se les intenta atribuir una serie de obligaciones y valores: "Las dos Vías de la Lealtad y del Deber Filial no se limitan a los samuráis. También incumben igualmente a los artesanos y comerciantes". Finalmente, para referirse al lugar que éstos ocupan dentro de la escala social. 
Sin embargo existen pocas referencias en el texto que nos permitan conocer en profundidad detalles sobre su actividad.

Respecto al sector servicios, indudablemente el ejército ocupa un lugar fundamental, preferente, teniendo en cuenta las características del samurái. En este sentido, tenemos que destacar una figura que existía en aquellos años llamada jindai o sustituto de guerra: cuando un samurái moría en combate y su hijo era muy pequeño para heredar, se nombraba un administrador de todos los bienes heredado, que, a cambio de un salario, administraba todos los bienes hasta que el hijo tuviese edad de hacerlo. En la obra de Yuzan, además de describir las obligaciones de esta persona, se critica el hecho de que trasmita a los herederos deudas que su padre no había contraído, que administre mal los bienes, o que se quede con los bienes del heredero y lo califica como "pillo sin principios":

existe aquel que no está dispuesto a traspasar a su heredero lo que le corresponde por edad o cuando lo hace deja las propiedades en malas condiciones y la casa por reparar y no hace ningún intento por restaurarla. Peor aún, puede trasmitir al heredero deudas que su padre no había contraído... ... Un hombre así es un pillo sin principios.

Una vez más se insiste en esta filosofía en criticar y condenar el endeudamiento innecesario, el robo o la mala administración.

Dentro del sector servicios, se le dedica mucha atención al comercio. En aquella época, y teniendo en cuenta que el transporte a lo largo de las costas no resultaba difícil, se desarrolló fácilmente el comercio, un comercio relativamente importante; pero sólo interior. El comercio exterior era prácticamente inexistente a partir del decreto shogunal de fronteras cerradas de 1639, el mismo año en que nació Yuzan. Todo extranjero que desembarcase en un puerto tenía que tratar cualquier cuestión con las personas designadas expresamente por el shogun (Segura, 2000, p.303).

En este sentido, en la obra de Yuzan no se hace referencia al comercio exterior. Pero, paradóiicamente, tampoco al transporte marítimo, a pesar de que existen numerosas islas en Japón y existía un comercio entre ellas. En cuanto a los comerciantes, con independencia de la terminología utilizada en la obra para denominarlos ("comerciantes", "vendedores",...), hay que decir que una parte importante de las alusiones son de tipo despectivo, utilizando expresiones como: "se convertirá en alguien semejante a un simple comerciante..."; "sólo es un comerciante en una piel de guerrero..."; "degrada la vía del guerrero rebajándola a la de un simple comerciante...". Esto último tiene su origen en la idea confuciana de desprecio al comerciante. Una religión que influyó notablemente en el Bushido. 
En definitiva, toda una serie de alusiones que ponen de relieve que esta actividad no era demasiado popular o bien vista dentro del mundo del Bushido y de los samuráis.

No obstante, en otras ocasiones, y al igual que sucede con los artesanos, también se aconseja o se pide un buen trato para los comerciantes: "no se debe de enviar a por pertenencias de los comerciantes y después dejar que esperen el dinero debido". En este caso, y en línea con el pensamiento del Bushido, no sólo se desaconseja el endeudamiento, sino que intenta proteger a los comerciantes de las posibles consecuencias negativas de dicho endeudamiento. De hecho, más adelante se afirma:

y aunque puedas no pagar todas las deudas de una vez y puedas hacer transacciones con los comerciantes, ciertamente debes pagarles algo de vez en cuando para no causar pérdida en infortunio a esta casta.

De este modo, lo mismo que ocurre con otras castas, con los comerciantes se expone en la obra de Yuzan cierto paternalismo y trato de favor, a pesar de las críticas que, por otro lado, se vierten contra este grupo social. Esto es lógico puesto que, con el desarrollo económico del período Tokugawa-que prácticamente coincide con la época en que se escribió el libro-, numerosos comerciantes incrementaron su prestigio y su fortuna y gozaron un trato especial en las ciudades-castillo de los daimios, pues monopolizaban el mercado urbano y abastecían de todo lo necesario a sus habitantes. De ahí que se les dé en el texto cierto trato de favor.

Finalmente, se menciona una actividad de los samuráis que consistía en prestar dinero a otras castas sociales y cobrarles altos intereses. En este sentido, en la obra se adopta una actitud muy crítica puesto que se censura que se haga a dichas castas, pero no que se lleve a cabo entre los propios samuráis: "es absolutamente incorrecto prestar dinero y cobrar intereses con usura sobre estos préstamos como si fueran simples compañeros de dormitorio" (p. 67). De este modo, la usura se ve, al menos en parte, como algo negativo y perjudicial porque viola la filosofía y la ética del Bushido (al perjudicar a los deudores siempre y cuando perteneciesen a castas inferiores), al igual que ocurría con la manera de pensar del Cristianismo, el Islam y el Judaísmo durante la Edad Media. Ver Grice-Hutchinson, (1995). 


\section{Recursos económicos}

En El código del samuray, aparece toda una variedad de recursos económicos tanto de origen natural como artificial, a algunos de los cuales (como las viviendas, por ejemplo), ya se ha ido haciendo referencia en los puntos anteriores. Así, se mencionan "montaña", "bosque", "agua", "caballos", "pan", "perro", "gato", "espadas", "armaduras", "arco", "ballesta", "cascos", "flecha", "lanzas", "alforjas", "sandalias", "cuenco", "monedero", "paja", "teteras", "la posesión de tierras", y el dinero: "devolver el dinero", "la existencia del dinero", "monedas", "oro", así como nombres específicos de las monedas utilizadas en el Japón de aquellos años, en concreto el "ryo". Si bien es cierto que en la época en que se escribió la obra se utilizaba el trueque en los intercambios comerciales, también se utilizaban las monedas. Podemos destacar, precisamente, el "ryo" como una moneda de oro típica del siglo XVII.

Pero lo más importante que se expone en la obra y se enjuicia es cómo administrar esos recursos. Los términos "ingresos", "gastos", "déficit", "ahorro", "ahorrar" y "economizar" son utilizados en algunos lugares del texto. Para este código de conducta, la frugalidad y la austeridad es algo muy importante en la vida de un guerrero y dedica descalificativos al que hace lo contrario: "degrada la vía del guerrero rebajándola a la del simple comerciante". De este modo, el ahorro es fundamental en la vida de un guerrero ya que tanto el ahorro como la austeridad y la frugalidad conllevan una serie de consecuencias positivas, al igual que hacer lo contrario las tiene negativas.

De hecho, cuando se gasta más que se ingresa, significa un déficit. En la obra de Yuzan se habla de "déficit en los gastos de su hogar", refiriéndose en este último caso al hogar del samurái. Asimismo, en el texto se alude a algunos aspectos de la administración de los recursos económicos de los señores o daimios:

en cuanto a los que tienen amplios ingresos, sin ver que están viviendo por encima de sus posibilidades, pueden hacer rápidamente un cambio en sus asuntos económicos, haciendo algún ahorro por un lado y reduciendo gastos...

Es evidente que se está criticando el exceso de gasto y se recomienda de forma clara y precisa el ahorro. De hecho, el apartado en donde se hacen estos comentarios se denomina frugalidad. Asimismo, también se critica el endeudamiento o, al menos el exceso del mismo y advierte de las consecuencias:

si intenta vivir como un gran vasallo e incurre en gastos innecesarios que le causan dificultades, por mucho que intente economizar, lo único que hace es estar casa vez más endeudado hasta llegar finalmente a la ruina total. 
En este sentido, el hecho de ahorrar y gastar con cuidado y sin exceso, de forma que ello no implique un endeudamiento excesivo $y$, en definitiva, se lleve a cabo una política de austeridad y frugalidad, es lo que en este código de conducta se denomina vía de la economía. Aun cuando el tema es algo más complejo, como se verá posteriormente.

\section{Normas de conducta: la vía de la economía}

A lo largo de los apartados anteriores se han analizado toda una serie de aspectos y cuestiones económicas contenidas en la obra de Yuzan. Como el lector habrá podido observar, la mayor parte de los datos positivos que describen la realidad económica japonesa se dan al presentar los criterios éticos que deben presidir la vida del samurái, y el comportamiento social, en general. En este sentido, vamos a exponer de forma resumida las normas de conducta económica referidas tanto a la conducta individual como al funcionamiento social, haciendo referencia a diversos aspectos de la economía. De hecho, hemos podido comprobar que lo más importante en El código del samuray son las normas de conducta, y no el análisis positivo de la realidad, de ahí que le dediquemos un apartado a hablar de las normas.

Además, consideramos que sistematizar las principales normas de conducta en sentido económico del Bushido es también una forma de acercarnos a la realidad económica de aquellos años; pues, en definitiva, muestran no sólo el modo de pensar acerca de la conducta adecuada, sino, al mismo tiempo, las prácticas reales, en la medida en que se separaban de tales normas.

Estas normas, aunque el libro no lo diga explícitamente, se apoyan en los principios básicos que son: Lealtad, valor, honor, justicia y honradez y sinceridad.

Hasta ahora hemos visto una serie de ideas de cómo se deben administrar los recursos: austeridad, ahorro, críticas al endeudamiento, en especial al endeudamiento excesivo, control del gasto, etc. Este tipo de ideas se plantean en un contexto de disciplina, en donde se le exigía al samurái un control total y absoluto de sus actos, un autocontrol, que incluía a la alimentación y a temas relacionados con la sexualidad, de ahí que se les exigiera que no incurriesen en lo que ellos consideraban un derroche y en excesos de cualquier naturaleza. Y que tuviesen que aplicar dicha disciplina en diversas vías, incluyendo la económica. De este modo, surge lo que en El código del samuray se denomina la vía de la economía: Vivir 
conforme a los propios medios y ser muy cuidadoso de no complacerse en ningún gasto innecesario, empleando el dinero sólo en lo necesario. Aunque también se critica en la obra que no se realicen gastos que sean necesarios. Tan mala es la avaricia como el despilfarro.

Se trata de un concepto económico que tiene bastante importancia, al ser primordial para la vida de los samuráis, y se trataba de algo que, al menos en teoría, estaban obligados a respetar.

Para el Bushido, como ya se ha mencionado anteriormente, economizar y tener un cierto excedente es algo muy positivo porque demuestra la solvencia de la persona. Pero si incurre en gastos innecesarios, y se endeuda de forma progresiva, tendrá cada vez más dificultades económicas y es precisamente dicha dificultad económica la que puede obligar a la persona que las tiene a hacer cosas fraudulentas. Además, puede arruinarse y arruinar a todos aquellos a los que debe dinero, de forma que el perjuicio que se causa a sí mismo puede extenderse a otras personas.

Por lo tanto, según este código de conducta, cuando alguien gasta más de lo que puede tiene déficit y dicho déficit aumenta sus deudas. En este sentido, las deudas son el resultado de acumular déficit a lo largo del tiempo. Así que estar endeudado es negativo, pues significa que se le debe dinero a una serie de personas que también pueden caer en esta situación por los ingresos que no reciben. Sin embargo, no se plantea que el endeudamiento pueda tener aspectos positivos, si se persigue realizar una inversión que en el futuro pueda generar más recursos y solucionar la situación de endeudamiento.

De este modo, tanto los grandes como los pequeños samuráis que están al servicio de alguien, deben siempre practicar la frugalidad para no tener un déficit en los gastos de su hogar; e incluso los que tienen amplios ingresos deben de controlarse, ahorrar y reducir sus gastos, en el caso de que estén viviendo por encima de sus posibilidades, de forma que puedan mantener su excedente. Así pues, en la obra se afirma que es necesario vivir conforme a los propios medios y ser muy cuidadoso de no complacerse en ningún gasto innecesario, empleando el dinero sólo en lo necesario.

Ahora bien, antes se mencionaba que los excesos no son buenos, y ello incluye al exceso de ahorro y la excesiva moderación en el gasto. Esto también es algo negativo, puesto que, según el texto:

no hacer otra cosa que hablar de economía y odiar gastar cualquier cosa, ahorrando y recortando en toda ocasión, así como deleitarse cuando se puede añadir una moneda 
a otra mediante cualquier estratagema tacaña, es adquirir una mentalidad consagrada al inmundo lucro y más adelante perder todo sentido de la decencia... Esta clase de personas lo que practica es la avaricia y no la economía.

Es evidente que la economía, para este código de conducta, es secundaria en relación a otros valores superiores.

Asimismo, tenemos que sacar a colación el rechazo profundo de esta filosofía a las prácticas corruptas de los funcionarios. En concreto al desfalco. Para el Bushido, "el robo a la administración del país es el crimen mayor que se puede cometer", tal y como se afirma en uno de sus capítulos. Incluso propone una solución al desfalco: "El funcionario ladrón debe ser castigado mediante la decapitación o crucifixión". Esto último está relacionado con el concepto de lealtad que tenía esta filosofía: lealtad no solo al señor sino al gobierno japonés representado por el Emperador y el Shogun.

\section{CUADRO $n^{\circ} 2$. La vía de la economía}

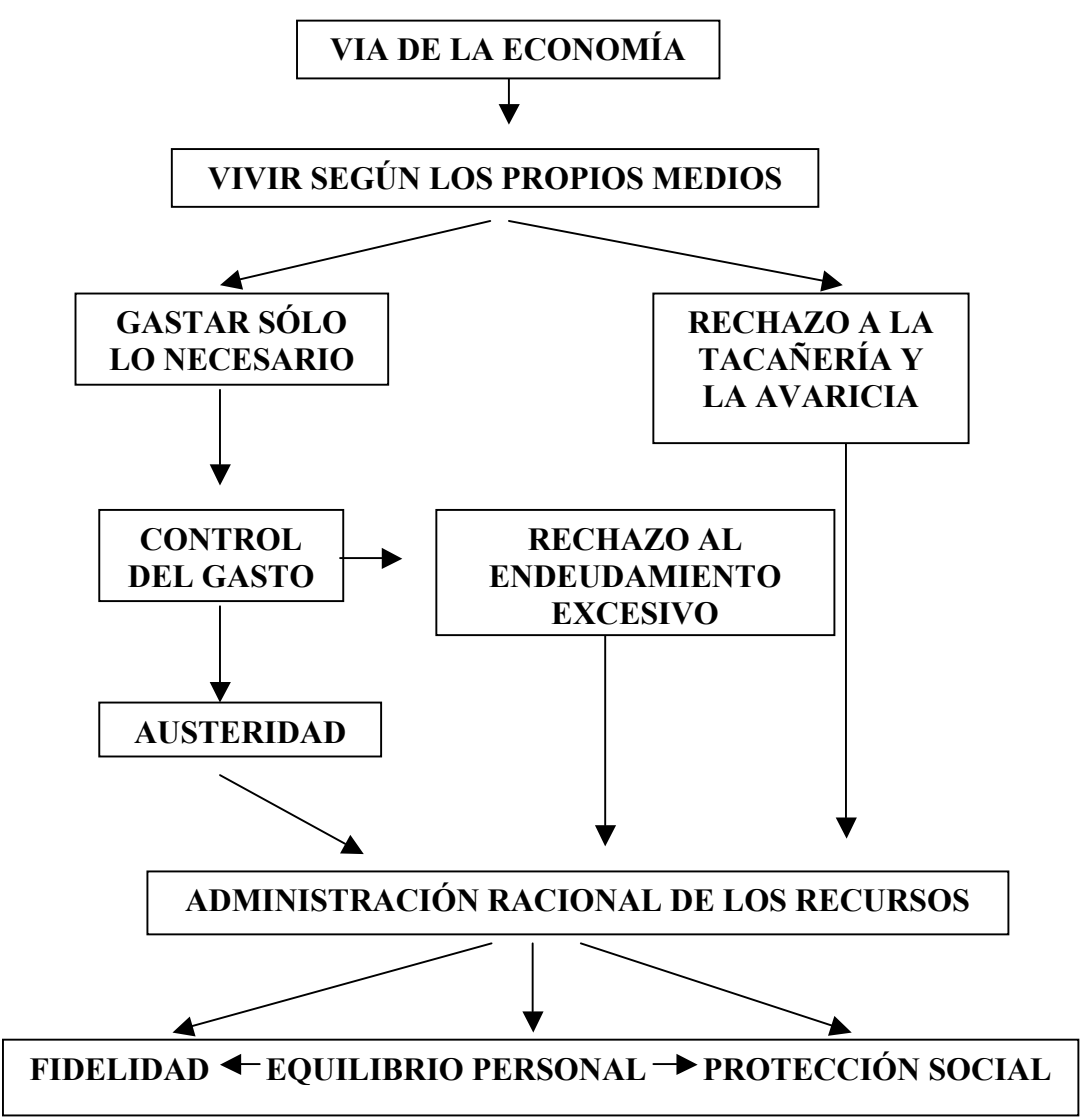

Fuente: elaboracion propia. 
Para este código la avaricia sería la conducta de la persona que "pierde todos sus instintos excepto el de acumular". De hecho, en el libro se afirma que la tacañería es algo que debe de aborrecerse en la vida de un samurái. De este modo, en el texto se diferencia con claridad la economía de la avaricia, puesto que el avaro cae en un exceso: exceso de ahorro, puesto que gasta demasiado poco, aun tratándose de gastos necesarios, y sólo piensa en acumular pero de manera exagerada, lo que en la obra se denomina "el inmundo lucro". Por el contrario, el que practica la economía hace justo lo contrario: gastar con moderación o en su justa medida y ahorrar; pero atendiendo al mismo tiempo a las necesidades que haya que satisfacer.

Por lo tanto, se trata de no excederse en ningún sentido, incluyendo el ahorro y la moderación de los gastos, ya que la avaricia es algo tan negativo como la ausencia de frugalidad o el endeudamiento excesivo. De hecho, en el texto se considera que la tacañería es algo más bien propio de los comerciantes y los campesinos, y especialmente de los comerciantes; pero se trata de un defecto que nunca debe de tenerlo un guerrero samurái, ya que es algo aborrecible y que hay que evitar a toda costa.

En este sentido, resulta interesante destacar la coincidencia con el pensamiento cristiano y musulmán, que también critican a la avaricia. Por ejemplo, en El Libro del Buen Amor (ver García y Aguilar, 2008), el Arcipreste de Hita sólo con escuchar al avaro ya se siente mal (ver el verso $246 \mathrm{~d}$ ). De igual modo, en El libro de las Banderas de los Campeones del poeta lbn Said (ver García, 2009), en los poemas 35 y 194, entre otros, se expone una desaprobación de tal conducta, describiendo la negativa impresión que en el estado de ánimo del poeta transmite su sola presencia.

De todos modos, aquí se plantea una novedad con respecto a los demás textos citados, al vincular la condena de la avaricia con las cualidades que deben definir el oficio de un samurái, vinculado con las armas y el servicio a su señor: "si antepone el dinero al deber y escatima gastarlo, ¿¿uánto más escatimará entregar su vida que es más preciosa?". En este caso, además de considerar la vida como un recurso económico, comparándola con el dinero y considerándola de más valor, se reflejan dos advertencias muy concretas. Por un lado, la preocupación excesiva por el dinero puede llevar a que la persona no cumpla con sus obligaciones. Y por otro, tales actitudes pueden arrastrar hasta la propia cobardía. Si el samurái no está dispuesto a sacrificar el dinero, mucho menos estará dispuesto a sacrificar su vida, lo que repercutirá en el servicio que está obligado a prestar. No hay que olvidar que la parsimonia es sinónimo de cobardía en China, y así lo hace saber 
el autor en el texto. En consecuencia, una de las obligaciones más sagradas o importantes para el Bushido, estar dispuesto a dar la vida por su señor, puede verse afectada precisamente por el amor desmedido por la riqueza.

En resumen, tal como se recoge en el cuadro $n^{\circ} 2$, hay tres cuestiones fundamentales contenidas en la denominada vía de la economía. En primer lugar, se defiende que el samurái debe vivir de acuerdo con sus posibilidades, ni derrochando, ni gastando menos de lo que sea razonable. Por tanto, se trata de no caer en ningún exceso, ni en el despilfarro que arrastra hacia el endeudamiento; pero tampoco en la avaricia y la tacañería. De este modo, cuando se trata de gastos necesarios estos no se consideran un derroche, sino una obligación.

En segundo lugar, tales recomendaciones para el control de los fondos nos sitúan ante un modelo de administración racional de los recursos, de algún modo coincidente con lo que la actual teoría económica plantea cuando habla de optimizar las decisiones humanas en el proceso de asignación de los factores económicos.

$Y$, finalmente, en tercer lugar, tales planteamientos no se defienden de manera arbitraria o por una simple cuestión de principios. Se busca, desde luego, una finalidad estrictamente económica, orientada a maximizar la utilidad personal del propio individuo, evitando su ruina personal, manteniéndolo a salvo de la bancarrota, al mismo tiempo que se salvaguarda la dignidad de su oficio. Pero, además, el comportamiento recomendado tiene una doble justificación externa al propio sujeto. Por una parte, no arruinar a terceros (campesinos, comerciantes y artesanos, a los que se les puede llegar a adeudar cantidades difíciles de soportar por sus economías, si se desatiende la correcta administración de los propios recursos, incurriendo en deudas excesivas, difíciles de pagar). Es decir, hay una finalidad claramente social. Por otra, servir escrupulosamente al daimio, tanto en lo que se refiere a la administración adecuada de sus bienes, como, de manera muy especial, al mantenimiento de la adecuada jerarquía de valores que garanticen la fidelidad en el cumplimiento del deber, no poniendo en peligro las condiciones vitales precisas para ello, incluidos el valor y el espíritu de sacrificio.

En realidad, en la obra, en el fondo, se plantea cómo utilizar los recursos disponibles con el objeto maximizar lo que para esta filosofía es casi una necesidad humana: la fidelidad. Esta fidelidad o cumplimiento del principio de lealtad al daimio incluye la defensa del clan y la reciprocidad por la protección que el daimio proporcionaba al samurái. 


\section{La pervivencia de la vía de la economía en el Japón actual}

El Bushido murió con su abolición oficial en 1868, aunque ello no quita que continuase presente en el Japón en la vida política, social, económica, etc. Sin embargo, 150 años después nos podemos preguntar si estos valores siguen presente en el Japón de hoy. Realizar un estudio en profundidad sobre la pervivencia de esta filosofía en el Japón de hoy requeriría mucho espacio que superaría con creces los límites de nuestro estudio'. De este modo, vamos a centrarnos en los aspectos principales de la vía de la economía, la cual estaba caracterizada por la austeridad y la frugalidad, apoyando el control del gasto, criticando el gasto elevado e innecesario, el déficit y el endeudamiento, sobre todo el endeudamiento excesivo; pero criticando, al mismo tiempo, la avaricia y la tacañería.

En este sentido habría que preguntarse si todos los anteriores preceptos de la filosofía del Bushido se mantienen en el Japón actual. Para ello nos detendremos en algunos datos relativos al sector público y al comportamiento de los hogares.

\section{CUADRO n 3. Deuda pública (\% del PIB)}

\begin{tabular}{|c|c|c|c|c|}
\hline Año & Japón & EE. UU. & Alemania & Corea del Sur \\
\hline 1991 & 63,5 & 66,4 & 29,3 & 14,6 \\
\hline 2000 & 137,9 & 53,0 & 58,9 & 17,1 \\
\hline 2011 & 222,1 & 98,0 & 78,6 & 31,5 \\
\hline 2012 & 229,0 & 103,5 & 79,8 & 32,2 \\
\hline 2013 & 232,5 & 105,4 & 77,5 & 35,4 \\
\hline 2014 & 236,1 & 105,7 & 74,7 & 37,3 \\
\hline 2015 & 231,7 & 105.3 & 71,0 & 39,5 \\
\hline 2016 & 235,6 & 107,1 & 66,2 & 40,0 \\
\hline
\end{tabular}

Fuente: OECD Factbook 2017: Economic, Environmental and Social Statistics.

Comencemos por anal lizar el comportamiento del sector público. En los últimos años se ha producido en Japón una notable expansión del gasto público, que ha dado

' Para más información sobre la pervivencia de los valores del Bushido en el Japón actual ver Aguilar (2010). 
lugar a un importante crecimiento de la deuda. Efectivamente el stock de deuda pública viva en Japón en 2016 se sitúa en torno al 235\% del PIB, según datos de la OCDE (ver cuadro $n^{\circ} 3$ ). Esta situación se debe principalmente a la herencia de la serie de medidas tomadas por el gobierno nipón en la crisis económica del 2008, que ya venía dando coletazos desde que en 1990 tuvo lugar otra burbuja inmobiliaria en ese país.

En este sentido, tanto el gobierno como el Banco Central de Japón siguieron la doctrina keynesiana más "ortodoxa": deteriorando las finanzas del Estado, pero sin apenas contribuir a la recuperación de la economía, e imponiendo una pesada carga en las generaciones venideras (García-Caro Núñez, 2008). Si comparamos la evolución de la deuda pública de Japón con la experimentada por Estados Unidos, Corea, y Alemania (cuadro ${ }^{\circ} 3$ ), podemos observar que la deuda pública japonesa ha aumentado de forma muy notable en el periodo 1991-2016. Si bien la deuda pública en Japón parte de niveles muy similares a los de Estados Unidos, a partir de 2000 empieza un incremento muy marcado que lleva a que en 2016 la deuda pública creciera un $274 \%$ respecto a 1991, mientras que en Estados Unidos la deuda pública se incrementa muchísimo menos. De este modo, el nivel de deuda pública como porcentaje del PIB en Japón es 2,2 veces superior al de Estados Unidos en 2016. Alemania y Corea del Sur se sitúan en niveles de endeudamiento mucho más bajo ese mismo año.

\section{CUADRO n 4. Déficit público (\% PIB)}

\begin{tabular}{|c|c|c|c|c|}
\hline Año & Japón & EE. UU. & Alemania & Corea del Sur \\
\hline 2000 & $-8,2$ & 1,4 & 0,9 & 4,1 \\
\hline 2010 & $-6,2$ & $-10,9$ & $-4,2$ & 1,5 \\
\hline 2011 & $-9,4$ & $-9,6$ & $-1,0$ & 1,7 \\
\hline 2012 & $-8,6$ & $-7,9$ & 0,0 & 1,4 \\
\hline 2013 & $-7,9$ & $-4,4$ & $-0,1$ & 0,6 \\
\hline 2014 & $-5,6$ & $-4,0$ & 0,5 & 0,4 \\
\hline 2015 & $-3,8$ & $-3,5$ & 0,8 & 0,5 \\
\hline 2016 & $-3,7$ & $-4,2$ & 1,0 & 1,7 \\
\hline
\end{tabular}

Fuente: OECD Factbook 2017: Economic, Environmental and Social Statistics. 


\section{CUADRO n 5 . Ahorro sobre el PIB (\%)}

\begin{tabular}{|c|c|c|c|c|}
\hline Año & Japón & EE. UU. & Alemania & Corea del Sur \\
\hline 2000 & 29,9 & 20,7 & 22,1 & 34,2 \\
\hline 2010 & 25,1 & 15,3 & 25,2 & 34,8 \\
\hline 2011 & 24,2 & 15,9 & 27,2 & 34,6 \\
\hline 2012 & 23,6 & 17,9 & 26,3 & 34,4 \\
\hline 2013 & 24,0 & 18,5 & 27,2 & 34,5 \\
\hline 2014 & 24,6 & 19,5 & 27,0 & 34,5 \\
\hline 2015 & 27,2 & 19,4 & 27,7 & 35,8 \\
\hline 2016 & 27,3 & 18,0 & 27,6 & 35,7 \\
\hline
\end{tabular}

Fuente: OECD Factbook 2017: Economic, Environmental and Social Statistics.

En lo que al déficit público se refiere, Japón no ha tenido un superávit durante el periodo considerado, sino que año tras año los gastos fueron siempre superiores a los ingresos (ver cuadro $n^{\circ} 4$ ). Es evidente que la política que predicaba el Bushido de frugalidad, control del gasto y exceso de endeudamiento no se cumple en Japón. Es cierto que el déficit público se reduce 4,6 puntos durante dicho período, pero otros países como Corea del Sur no tienen déficit en ninguno de esos años, Alemania solo en tres, aunque con niveles de déficit más reducidos. EE.UU es el único país que tiene cifras de déficit más similares a Japón.

En lo que respecta a la tasa de ahorro sobre el PIB, (ver cuadro ${ }^{\circ} 5$ ) una de las características más distintivas del dato japonés frente al de Corea del Sur es que los primeros ahorran menos durante todo el período 200-2016 estudiado. Si lo comparamos con EE.UU es mayor durante el mismo período, pero, en cambio con respecto a Alemania tiene una tasa de ahorro menor excepto en los años 2000 que lo superaba en casi 8 puntos y 2001, este último con unas tasas de ahorro similares a Alemania.

Asimismo, si comparamos la evolución de la tasa de ahorro japonesa con la de otros países observamos que, aunque en otro de los países estudiados la tasa de ahorro también se reduce, $-2,7$ puntos en EE.UU- es en Japón donde más se reduce dicha tasa, hasta situarse en valores similares a los de Alemania. En este último país y en Corea, la tasa de ahorro se incrementa 5,5 y 1,5 puntos respectivamente durante el período considerado. 
Son varios los trabajos que analizan las causas del descenso de la tasa de ahorro japonesa, señalando los cambios demográficos, y los cambios de "preferencia de tiempo" como posibles causas (Takayama 2015) o cambios en la tasa de crecimiento de la productividad total de los factores (Chen 2009).

Ante estos datos no se pretende juzgar ni la política económica del gobierno japonés, ni la evolución económica japonesa. Sólo se pretende analizar si se han mantenido los preceptos del Bushido de acuerdo con el comportamiento político adoptado. Y la respuesta está bastante clara. En definitiva, se puede afirmar que toda esa política de austeridad, de control del gasto, de evitar el alto nivel de endeudamiento, etc. a la que el Bushido hace referencia, no se cumple en este caso, y el gobierno ha seguido una línea de actuación totalmente distinta. De forma que la llamada Vía de la economía no se cumple en el Japón de hoy.

Por último, otros de los postulados de la vía de la economía es el rechazo a la corrupción en el sector público y a las prácticas corruptas de los funcionarios. Para esta filosofía, el desfalco, el robo a la administración del país es un crimen muy grave que debe de ser castigado contundentemente. Vamos a analizar que sucede en el Japón de hoy con respecto a esta cuestión.

Aunque no pretendemos entrar a fondo en la política japonesa, no es ningún secreto que en los últimos años la han salpicado numerosos escándalos. Hechos como la dimisión del primer ministro japonés Abe-Shinzo en agosto de 2006 cuyo gabinete estaba, desde su formación, en llamas, salpicado por una larga serie de escándalos por culpa de los ministros².

Asimismo, un informe del Centro para la Intregridad Pública (The Center for Public Intregrity) con sede en Washington, que hizo mediciones en 25 países, colocaba a Japón en lo que a corrupción y escándalos políticos se refiere, en una situación no muy favorable en el promedio de países como Filipinas, Argentina o Brasil (ver Rodao, 2015, pp. 38-42). Asimismo, en los últimos 20 años, situaciones como esta han salpicado la vida política japonesa; lo que se ha expuesto anteriormente era solo un ejemplo, un caso particular. Para más información sobre esto último ver Aguilar (2010).

Para profundizar más en el tema de la corrupción del sector público en Japón, vamos a utilizar el Indice de Percepción de la Corrupción (IPC). Este índice, publicado por la Organización No Gubernamental Transparencia Internacional se creó en

2 Uno de ellos, el de Agricultura, optó por el suicidio después de descubrirse que estaba implicado en un escándalo de sobornos y fraude. 
1995 como un indicador compuesto para medir las percepciones sobre corrupción en el sector público según la percepción de empresarios, expertos y analistas del país, en distintos países del mundo. La corrupción se mide en una escala de cero (percepción de muy corrupto) a cien (percepción de ausencia de corrupción)³.

Durante los últimos 20 años, tanto las fuentes empleadas para compilar el índice como la metodología se han ido modificando y perfeccionando. En 2012 se incorporaron cambios importantes a la metodología para que se pudieran comparar las puntuaciones en el tiempo algo que no era posible antes.

\section{CUADRO $n^{\circ} 6$. Índice de percepción de la corrupción}

\begin{tabular}{|c|c|c|c|c|}
\hline Año & Japón & Alemania & EE. UU. & Corea del Sur \\
\hline 2010 & 78 & 79 & 71 & 54 \\
\hline 2011 & 80 & 80 & 71 & 54 \\
\hline 2012 & 74 & 79 & 73 & 56 \\
\hline 2013 & 74 & 78 & 73 & 55 \\
\hline 2014 & 76 & 79 & 74 & 55 \\
\hline 2015 & 75 & 81 & 76 & 56 \\
\hline 2016 & 72 & 81 & 74 & 53 \\
\hline
\end{tabular}

Fuente: Transparency Internacional. Datos Macro. Elaboración Propia.

En el cuadro $n^{\circ} 6$ podemos observar que Japón ha obtenido 73 puntos en el IPC. Su puntuación ha crecido en el último año, luego en este tiempo ha mejorado la percepción de que los japoneses tienen respecto a la corrupción en el sector público del país. No obstante el IPC de los últimos 7 años ha disminuido de manera que la sensación de corrupción en el sector público ha crecido. Además en el 2017 tanto Alemania como EE. UU. tenían una posición mejor que Japón. Corea del Sur es el país que tenía un Índice más próximo a cero y era el peor de los tres. Lo cual no es de extrañar teniendo en cuenta que su última presidenta está en prisión por un caso de corrupción ocurrido en 2016.

\footnotetext{
${ }^{3}$ El IPC utiliza diversas fuentes de datos que recogen la evaluación sobre una variedad de comportamientos en el sector público. Recogemos aquí algunos de ellos: Soborno, desvío de fondos públicos, uso de la función pública para beneficio personal, nepotismo en la Administración Pública, etc.
} 
En definitiva, al haber empeorado el IPC en cinco puntos $y$, teniendo en cuenta los numerosos casos de corrupción que han tenido lugar en Japón, podemos afirmar que el precepto del rechazo a la corrupción del sector público no se cumple del todo, aunque tampoco pretendemos afirmar que Japón sea un país corrupto. Pero si es cierto que el IPC ha empeorado en el período 2010-2017 y que la sensación de corrupción en el sector público había aumentado.

\section{Una reflexión adicional sobre Bushido y la situación econó- mica actual}

Han pasado ya cuatrocientos años desde que Daidoji Yuzan escribió El Código del samuray. Sin embargo, por mucho que el mundo haya podido evolucionar desde entonces, y los cambios hayan sido profundos y numerosos, parece que hay determinadas ideas que siguen siendo igual de válidas a comienzos del siglo XXI como a principios del siglo XVI.

Por ejemplo, en lo que a la vía de la economía se refiere, ideas como el ahorro, la austeridad, las consecuencias de un exceso de gasto y de endeudamiento, los periuicios que conlleva la codicia, etc., son cuestiones que se abordaban en el siglo XVly que hoy en día son sacadas de nuevo a colación en las actuales circunstancias económicas en las que se encuentra el mundo

Ramón Tamames (ver Tamames, 2009, p. xi) afirmó que ha sido una codicia desmesurada una de las causantes de la situación actual que ha llevado a déficit desorbitados, bajada del consumo y de la inversión, caída del PIB y tasas de paro muy altas, incluso en países con una tasa de desempleo tradicionalmente bajas como Japón o EE. UU.

Podríamos afirmar que se ha producido una vulneración de la vía de la economía, y debido precisamente a dicha vulneración se ha producido primero la crisis y luego la recesión que hemos padecido.

Por tanto, se puede afirmar que la vía de la economía puede ser una advertencia de las consecuencias que conlleva la ejecución de una serie de prácticas, como se ha expuesto anteriormente, y que se tradujo en una grave situación económica calificada por algunos como "la primera gran depresión del siglo XXI" (ver Tamames, 2009, p. x), que ha afectado prácticamente a todo el mundo y de la que no ha sido fácil salir, pero que, para su resolución, es necesario la realización de una serie de reformas que incluyan o tengan en cuenta, al menos, a la vía de la 
economía. Probablemente los programas de ajuste y de reducción del gasto y del déficit público sea buena muestra de ello.

De este modo, podemos afirmar que la vía de la economía no está pasada de moda sino todo lo contrario. Se puede hablar de una interconexión entre dicha vía y la economía real, incluyendo, como es lógico, a la vida de las personas, ya que si hubiese menos codicia, y más control o autocontrol en determinadas actuaciones de las personas -que es lo que predicaba el Bushido-, entonces muy probablemente no se hubiera producido una crisis como la sufrida 0 , al menos, sus consecuencias no hubiesen sido tan perniciosas.

\section{Consideraciones finales}

De acuerdo con el estudio realizado, puede concluirse que en El código del samuray, encontramos un amplio contenido de carácter económico, puesto de relieve en las referencias que aparecen en el texto acerca de la vida económica de su tiempo, en las ideas expuestas sobre gestión de recursos y sobre las consecuencias sociales de la misma; $y$, muy en especial, por la abundancia de normas éticas sobre conducta económica.

En este sentido, existe en el libro un amplio vocabulario de contenido económico que se extiende por toda la obra, con una terminología que se aplica para exponer diversos comportamientos en la vida diaria de los samuráis que el autor tiene interés en destacar.

El tratamiento que hace de los temas económicos es fundamentalmente de carácter microeconómico, y está dirigido hacia las economías domésticas y a la actividad productiva, centrándose en los aspectos negativos que tiene una mala administración de recursos y sus consecuencias. En cambio, los temas de carácter macroeconómico son prácticamente inexistentes a lo largo del texto. Las únicas referencias, que además tampoco resultan demasiado precisas en este sentido, van dirigidas a advertir de las consecuencias sociales de una política fiscal mal aplicada o de una mala administración económica, -injusta o desigual, corrupta o abusiva- que repercute en el contexto social inmediato.

De todos modos, el libro de Yuzan demuestra una gran veracidad y realismo en los datos económicos suministrados, que nos acercan a la vida cotidiana del Japón y a su organización política, económica y social en los inicios de la Edad Moderna (1868). Además mediante el estudio del contenido económico de este código de 
conducta, se puede ver cómo funcionaba en términos económicos el Japón de aquellos años, y también nos da una idea de la forma de pensar sobre cuestiones económicas tanto en términos positivos como normativos.

Pero sobre todo, hay que destacar la abundancia de juicios críticos sobre temas económicos que se extienden por toda la obra, así como las recomendaciones pertinentes vinculadas con los mismos. De este modo, resulta más importante en la obra de Yuzan el contenido normativo que el análisis positivo de la realidad; aun cuando tal contenido normativo encuentre apoyos consistentes en el propio análisis positivo. En este sentido, destacamos, el rechazo al endeudamiento excesivo, la necesidad de ahorrar, la frugalidad, el rechazo a la avaricia y a la tacañería, el rechazo y la prohibición del fraude al Estado y la correspondiente condena de la corrupción de los funcionarios. En especial hay que destacar la denominada "vía de la economía", como modelo de comportamiento económico recomendado en El código del samuray. Una vía de la economía que no se cumple en el Japón actual, puesto que toda esa política de austeridad, de control del gasto, de evitar el alto nivel de endeudamiento, etc. a la que el Bushido hace referencia, no se cumple en este caso, y el gobierno japonés ha seguido una línea de actuación en la política económica muy diferente.

De todos modos, desde una perspectiva actual consideramos que el mensaje principal que podemos sacar del texto de Yuzan es que la administración racional de los recursos no es algo actual, sino que ya, por diversos motivos, se predicaba en el siglo XVII en un país tan lejano como es el Japón. Además, algunas de las recetas que hoy en día se proponen para superar los problemas económicos actuales tales como la austeridad, el control del gasto etc. ya se recomendaban en aquella época.

Las consecuencias de una mala administración de recursos pueden ser muy negativas y pueden tener consecuencias graves para el futuro. Eso fue lo que el Bushido nos enseñó y no estaría de más que tanto gobernantes actuales como ciudadanos, aprendan la lección y, al menos, tengan en cuenta que ciertas actuaciones en el ámbito económico -exceso de gasto y de endeudamiento, etc.- pueden tener, y de hecho tienen, determinadas consecuencias que hay que prevenir para el futuro. Quizás, el aprender de estas recetas económicas puedan servir, tal y como esta filosofía pretendía, para proteger al individuo y a la sociedad en general. Esa economía del samurái o del guerrero que se expone a lo largo del libro, y en la que se nos muestra como dicho samurái debía de administrar los recursos de forma eficiente y racional, nos pueda servir como ejemplo en el mundo de hoy. Un ejemplo de esto último podría ser el principio de equilibrio presupuestario y control del déficit en los países de la Unión Europea. 


\section{Bibliografía}

Aguilar GÓmEZ, J. (2009) Economía y filosofía oriental: el contenido económico de El Código del Samuray". Universidad de Málaga. Tesis Doctoral.

- (2010) "Los cuatro libros sagrados del confucianismo: una lectura económica". Revista Empresa y Humanismo. Vol. XIII, n²/10.

- (2011) El contenido económico del libro sagrado budista: el Dhammapada. Revista Empresa y Humanismo. Vol. XV, n 2/12.

Chen, K., ImRohoroglua, A., y Imrohoroglu, S. (2009) "The Japanese Saving Rate". American Economic Review. Vol. 6, $\mathrm{n}^{\circ} 5$.

Cleary, T. (1998) El arte japonés de la guerra. El Bushido en la economía y en la política del Japón actual. Madrid, EDAF.

DifFenderfFer, B. (2007) El Líder Samurái. Madrid, Temas de Hoy.

García-Caro Núñez, A. (2008) "La deuda pública en Japón". Observatorio Latinoamericano de la Economía y la Sociedad del Japón. Vol. I, n 3.

García Lizana, A. y Aguilar Gómez, J. (2008) "La economía en el Libro del Buen Amor: sobre avaricia y pobreza". En Toros, F. y Haywood, L. (coord.) (2008) Juan Ruiz Arcipestre de Hita y el Libro del Buen Amor. Alcalá la Real, Ayuntamiento de Alcalá la Real, pp.195-204.

García lizana, A. y Calero Secall, M. I. (2009) "La economía en el Libro de las Banderas de los Campeones". Estudios de Frontera. Alcalá la Real, Ayuntamiento de Alcalá la Real.

García lizana, A. y Aguilar Gómez, J. (2011) "El tema de las riqueza en las tradiciones de occidente y oriente: algunas reflexiones sobre El Libro del Buen Amor, el Dhammapada y el Código del Samuráy", en ToROS, F. y GodinAs, L. (2011) Juan Ruiz Arcipestre de Hita y el Libro del Buen Amor. Alcalá la Real, Ayuntamiento de Alcalá la Real, pp. 115-122.

GrICE-HutCHINSON, M. (1995) Ensayos sobre el pensamiento económico en España. Madrid, Alianza.

Hawkins, V. y Gaskin, C. (2008) Breve historia de los samuráis. Madrid, Nowtilus. 
López Vera, J. (2016) Historia de los Samuráis. Madrid, Satori.

Martos, J.A. (2006) "Samurais". Clío. № 51. Madrid.

Martín Alarcón, P. (2001) Japón: origen y forja. Mitología religión y filosofía. Málaga, Asociación deportiva y cultural Daysu.

Nitobe, I. (2002) El Bushido. El alma del Japón. Barcelona, Olañeta.

Segura Simón, F. (2000) Manual de Historia Económica Mundial y de España. Madrid, Centro de Estudios Ramón Areces.

Rati, O. y Westbrook, A. (2005) Secretos de los Samurais. Madrid, Paitotribo.

Rodao, F. (2015) "Crisis y continuidad en el sistema político japonés". Jornadas sobre el desarrollo y cooperación en Asia. Universidad de Vigo.

Romero Fernández, A. (2006) "Bushido. Código del Samurái". Revista de Historia. №359, pp. 8-31.

Rubio, C. (2017) "Samuráis. Las guerras entre clanes de Japón". Historia. National Geographic.

Clements, J. (2010) Los samuráis. Barcelona, Crítica.

Segura Simón, F. (2000) Manual de Historia Económica Mundial y de España. Madrid, Centro de Estudios Ramón Areces.

Takayama, K. (2015) "Why does Japan`s Saving Rate Decline So Rapidly? Policy Research Institute. Ministre of Finance. Japan.

Tamames, R. (2005) "La condición económica de Don Quijote y Sancho en la sociedad española del siglo de oro. Información Comercial Española ${ }^{\circ} 824$. Madrid, pp. 141-154.

Tamames, R. y Gallego, S. (2006) Diccionario de Economía y Finanzas. Madrid, Alianza.

Tsunemoto, Y. (2004) Hagakure. El libro del Samurái. Barcelona, Olañeta.

- (2005) Bushido. El camino del Samurái. Barcelona, Paidotribo.

Yuzan D. [S XVI] (2011) El Código del Samuray. Versión de A.L. Sadler. Madrid, EDAF. 